\title{
ZSI Based Speed Controller for Three Phase Induction Motor
}

\author{
S. R. Awasthi, Jitendra Ahir, Prakash Narayan Tiwari
}

\begin{abstract}
This paper proposes a z source inverter based speed controller for controlling the speed of three phase induction motor. The induction motor is used in several industries for making the work easier and more reliable. Some times it is necessary to control the speed of induction motor, the speed of motor is controlled manually which takes much time and during speed controlling the power loss also increases. Therefore, this paper publish a less power consuming and reliable controller that control the speed of motor without using external dc to dc converter.
\end{abstract}

Keywords- Induction motor, $z$ source inverter, speed controller, pulse width modulation

\section{INTRODUCTION}

The induction motor is an electrical device for producing rotational energy by converting electrical energy into mechanical energy [1]. The induction motor can be either single phase or three phase. Mostly, the three-phase induction motor are widely used in several industries for grinding, mixing, pumping of fluid or for proving air ventilation in large factories [2]. Single phase induction motors are mostly used at small scale industries and in households for running the washing machines, drilling machines and blowers. Therefore, it is very important to control the speed of such types of induction motor [3].

Conventionally, for controlling the speed of three phase induction motor various techniques were developed such as voltage control, frequency control by changing the number of poles, voltage source inverter-based speed controller, current source inverter-based speed controller etc [4]. The above-mentioned conventional methods involve in complexity and requires external dc to dc converter. Thus, it is required to developed more simple and economical technique for speed controlling of three-phase induction motor.

The ZSI preferably a source inverter that uses only single level for stepping up or down the alternating output voltage from the direct current input source. [5] The use of this methodology eliminates the disadvantages of prior art techniques like in current source and voltage source inverter in which the output of inverter is found to be high or low than the input dc voltage [6], [7]. The proposed inverter does not require any external dc to dc converter hence, reduces the size of the system and improve the performance by increasing the efficiency of speed controller [8]. The use

Revised Manuscript Received on September 14, 2019.

S. R. Awasthi, Department of Electrical \& Electronics Engineering, Rabindranath Tagore University, Bhopal, MadhyaPradesh, India.

Jitendra Ahir, Department of Electrical \& Electronics Engineering, Rabindranath Tagore University, Bhopal, MadhyaPradesh, India.

Prakash Narayan Tiwari, Department of Electrical \& Electronics Engineering, Rabindranath Tagore University, Bhopal, MadhyaPradesh, India. of Induction motors over dc motors and synchronous motor are widely used because of the following reasons. Some of the advantages of using induction motor over other motors are compact size, highly efficient, cost effective, reliable, robust and does not require any extra mechanism for proving excitation. These advantages make the induction motor more popular in several traction vehicles. These motors are controlled by applying regenerative braking and controls the torque thereby controlling the speed.

\section{PROPOSED SYSTEM}

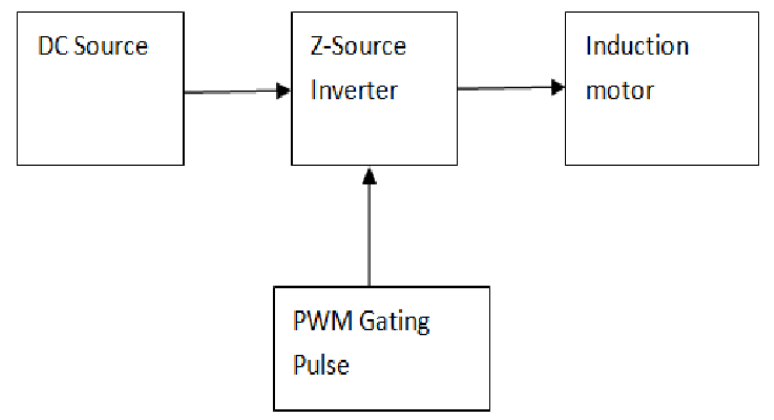

Fg.1 Block Diagram of Proposed System

Fig. 1 represents the block diagram of proposed system, it comprises of a dc supplying source for providing dc power, $\mathrm{z}$ source inverter connected to the dc source for receiving input dc power and converting it into ac output power after speed controlling process, a pulse width modulation for generating gate pulse supplied to the $\mathrm{z}$ source inverter and the induction motor acting as a load whose speed is to be controlled.

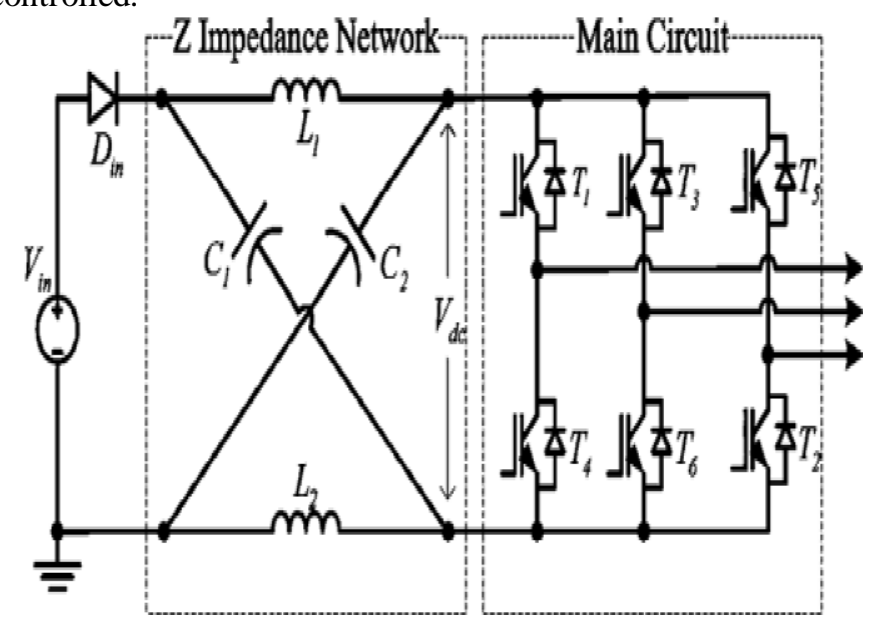

Fig.2 represents the circuit diagram of $\mathrm{z}$ source inverter 
Pulse width modulation provides the flexible output ac power by supplying gate pulse to the inverting circuit. Fig.2 represents the circuit diagram of $\mathrm{z}$ source inverter. It comprises of two stages; in first stage the dc circuit is used for improving the dc current and controlling the speed of induction motor. In second stage the controlled ac voltage is obtained from the inverting circuit and transferred this control ac voltage to three phase induction motor. The value input voltage, inductances, capacitances and switching frequency is represent table. 1
Table I: ZSI Parameters

\begin{tabular}{|l|l|}
\hline In put voltage VIN & $400 \mathrm{~V}$ \\
\hline Inductances $(\mathrm{L}=\mathrm{L} 1=\mathrm{L} 2)$ & $300 \mu \mathrm{H}$ \\
\hline Capacitances $(\mathrm{C}=\mathrm{C} 1=\mathrm{C} 2)$ & $360 \mu \mathrm{F}$ \\
\hline Switching frequency Fs & $20 \mathrm{KHZ}$ \\
\hline
\end{tabular}

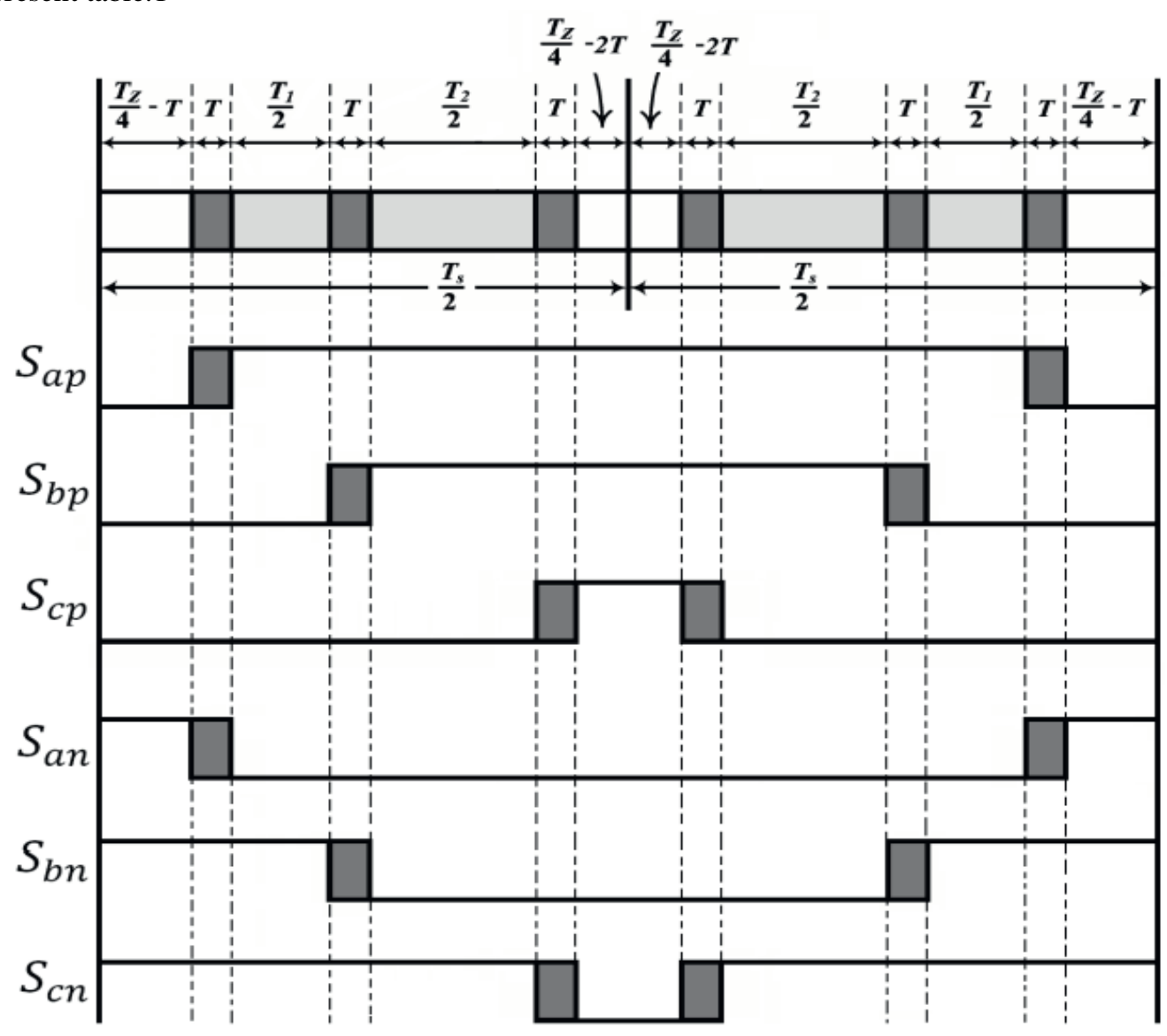

\section{Fig.3 Pulse Width Modulation Controlling Scheme}

The firing angle controlling through gate pulse width modulation is shown by fig.3. In this figure the operating state of thyristor is shown at different firing angle. There are total 6 switches in total, out of which two thyristor switches operated at a time. The controlling of firing angle by using different switches is shown above figure.

The main purpose of using $\mathrm{z}$ source inverter for controlling the speed of three phase induction motor is that it provides fast and reliable operation with less energy consumption. Due to the simplification of open loop pulse width modulation is widely used for controlling the speed of induction motor in several industries. Usually the induction motor is used with $50 \mathrm{~Hz}$ power supply for the purpose of stable speed applications. In case for the application of variable speed, the frequency is need to be changed and with the change in frequency the voltage must be also be changed in same proportion. 


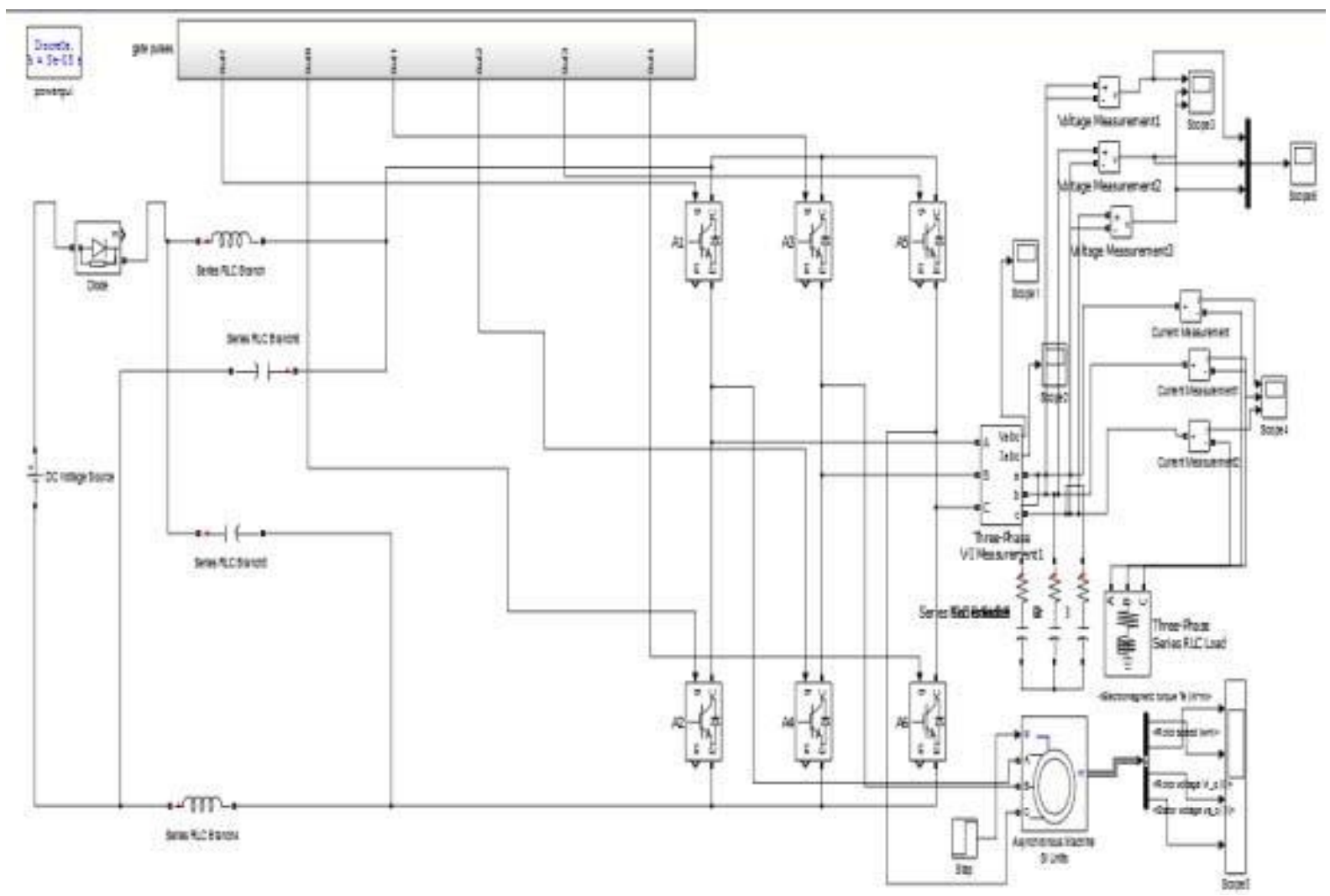

Fig.4 Schematic Diagram of Proposed System

The simulation diagram of proposed system is shown by fig. 4 which consist of three phase induction motor coupled with three phase $\mathrm{z}$ source inverter for controlling the ac output power from dc bus. The pulse width modulation produced from the gate pulse is used to control all of the switches for performing control action.

\section{SIMULATION RESULT}

The gate pulse generated for controlling the inverter switches S1, S2, S3, S4, S5 and S6 is shown by fig.5. The stator voltage waveform is produced after controlling the speed of induction motor is represented in fig. 6

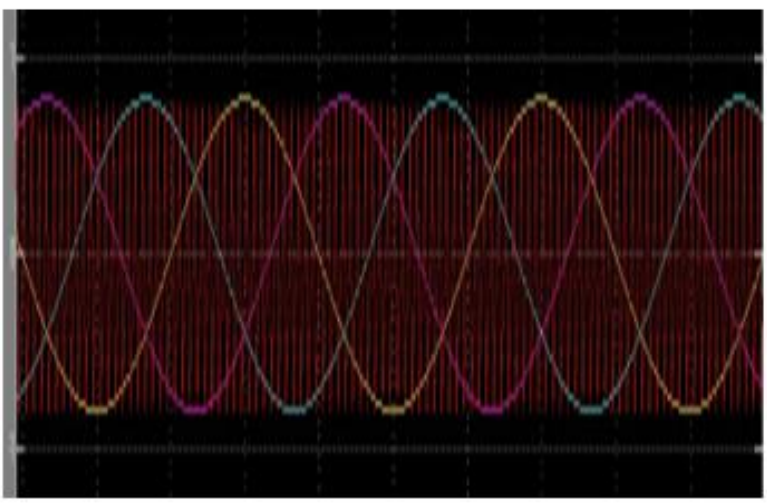

Fig. 5: Gate pulse generation using PWM control

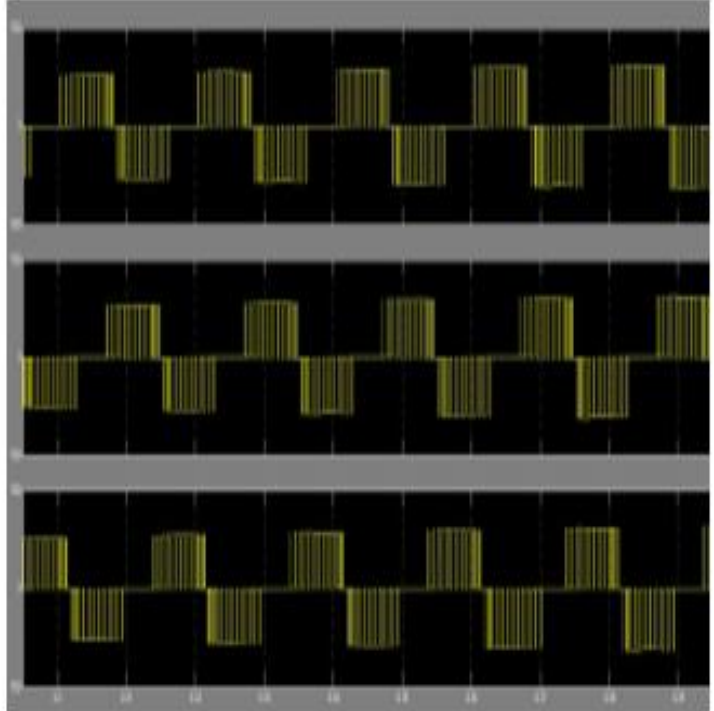

Fig. 6: Stator voltage $(\mathrm{Va}, \mathrm{Vb}, \mathrm{Vc})$ 


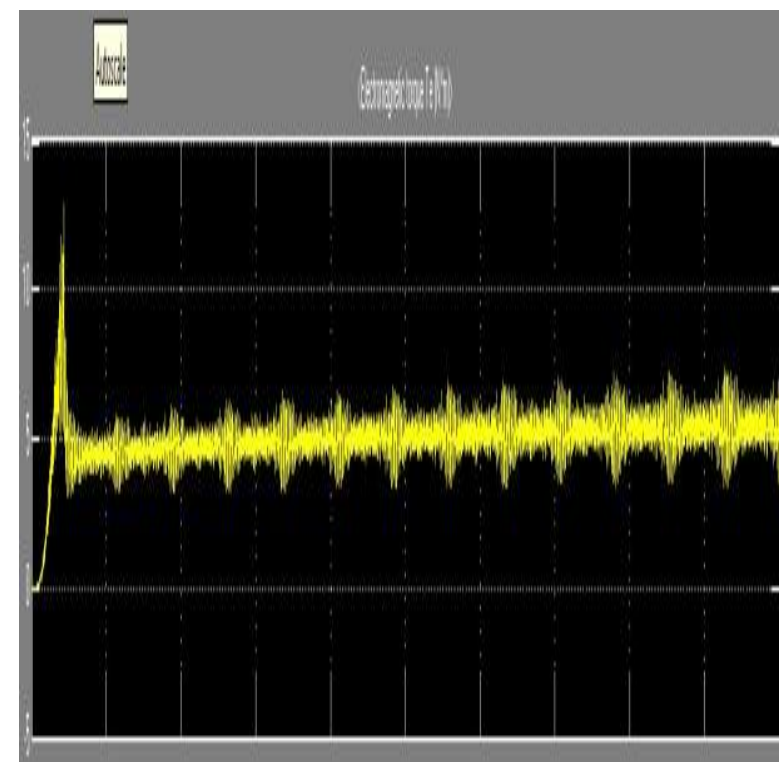

Fig.7 Generated Torque by motor

The torque developed in three phase induction motor during the operation of switches or during the speed controlling process is represented by the waveform given in figure.7. The complete the experiment is performed in MATLAB Simulink by connecting the block of electrical component together.

\section{CONCLUSION}

The induction motor is used in several industries for grinding, mixing or for the purpose of cooling the industrial products. Conventionally, the speed of such motor is controlled manually which is time consuming and a lot of power is wasted in doing so. Therefore, it is requiring to develop a system which can control the speed of three phase induction motor automatically. In this paper the ZSI based circuit is designed for controlling the speed of three phase induction motor. The whole experiment is performed in the MATLAB software through the simulation and suitable coding. The output waveform generated during speed controlling is shown in fig.5, 6 and 7.

\section{REFERENCE}

1. A. Boglietti, "Induction Motor," 2011.

2. J. Bird, "Three-phase induction motors," in Electrical and Electronic Principles and Technology, 2018.

3. L. M. PERKINS, "The Single-Phase Induction Motor," Trans. Am. Inst. Electr. Eng., 1925.

4. R. D. Seidler, D. C. Noll, and G. Thiers, "Feedforward and feedback processes in motor control," Neuroimage, 2004.

5. O. Ellabban and H. Abu-Rub, "Z-Source Inverter: Topology Improvements Review," IEEE Ind. Electron. Mag., 2016.

6. W. T. Franke, M. Mohr, and F. W. Fuchs, "Comparison of a Z-source inverter and a voltage-source inverter linked with a DC/DC-boost-converter for wind turbines concerning their efficiency and installed semiconductor power," in PESC Record - IEEE Annual Power Electronics Specialists Conference, 2008.

7. A. Ravindranath, S. K. Mishra, and A. Joshi, "Analysis and PWM control of switched boost inverter," IEEE Trans. Ind. Electron., 2013.
8. S. S. Nag and S. Mishra, "Current-fed switched inverter," IEEE Trans. Ind. Electron., 2014. 